\title{
Approximate Multi-Jensen, Multi-Euler-Lagrange Additive and Quadratic Mappings in $n$-Banach Spaces
}

\author{
Tian Zhou Xu \\ School of Mathematics, Beijing Institute of Technology, Beijing 100081, China \\ Correspondence should be addressed to Tian Zhou Xu; xutianzhou@bit.edu.cn \\ Received 26 April 2013; Accepted 31 July 2013 \\ Academic Editor: Krzysztof Ciepliński
}

Copyright (C) 2013 Tian Zhou Xu. This is an open access article distributed under the Creative Commons Attribution License, which permits unrestricted use, distribution, and reproduction in any medium, provided the original work is properly cited.

We prove the generalized Hyers-Ulam stability of multi-Jensen, multi-Euler-Lagrange additive, and quadratic mappings in $n$ Banach spaces, using the socalled direct method. The corollaries from our main results correct some outcomes from Park (2011).

\section{Introduction and Preliminaries}

In 2005, Prager and Schwaiger (see [1] and also [2]) introduced the notion of multi-Jensen functions with the connection with generalized polynomials and obtained their general form. In 2008, (see [3]) they also proved the Hyers-Ulam stability of multi-Jensen equation, whereas Ciepliński (see $[4,5]$ ) showed its generalized stability: in the spirit of Bourgin (see [6]) and Găvruța (see [7]), and in the spirit of Aoki (see [8]) and Rassias (see [9]). Recently, some further results on the stability of multi-Jensen mappings were obtained in [10-14]. We refer the reader to [15-19] for more information on different aspects of stability of functional equations.

In this paper, we deal with the generalized Hyers-Ulam stability of multi-Jensen, multi-Euler-Lagrange additive, and quadratic mappings in $n$-Banach spaces. The corollaries from our main results correct some outcomes from [20]. The results of Sections 2 and 4 generalize those from [12].

The concept of 2-normed spaces was initially developed by Gähler [21, 22] in the middle of the 1960s, while that of $n$-normed spaces can be found in $[23,24]$. Since then, many others have studied this concept and obtained various results (see [23, 25-27]).

Throughout this paper, $\mathbb{N}$ stands for the set of all positive integers and $\mathbb{R}$ represents the set of all real numbers. Moreover, we fix two positive integers $k$ and $n$.

We recall some basic facts concerning $n$-normed spaces.

Definition 1. Let $n \in \mathbb{N}$ and let $X$ be a real linear space with $\operatorname{dim} X \geq n$, and let $\|\cdot, \ldots, \cdot\|: X^{n} \rightarrow \mathbb{R}$ be a function satisfying the following properties:
(N1) $\left\|x_{1}, \ldots, x_{n}\right\|=0$ if and only if $x_{1}, \ldots, x_{n}$ are linearly dependent,

(N2) $\left\|x_{1}, \ldots, x_{n}\right\|$ is invariant under permutation,

(N3) $\left\|\alpha x_{1}, \ldots, x_{n}\right\|=|\alpha|\left\|x_{1}, \ldots, x_{n}\right\|$,

(N4) $\left\|x+y, x_{2}, \ldots, x_{n}\right\| \leq\left\|x, x_{2}, \ldots, x_{n}\right\|+\left\|y, x_{2}, \ldots, x_{n}\right\|$

for all $\alpha \in \mathbb{R}$ and $x, y, x_{1}, x_{2}, \ldots, x_{n} \in X$. Then the function $\|\cdot, \ldots, \cdot\|$ is called an $n$-norm on $X$, and the pair $(X,\|\cdot, \ldots, \cdot\|)$ is called an $n$-normed space.

A sequence $\left\{x_{j}\right\}_{j \in \mathbb{N}}$ in an $n$-normed space $X$ is said to a converge to some $x \in X$ in the $n$-norm if

$$
\lim _{j \rightarrow \infty}\left\|x_{j}-x, y_{2}, \ldots, y_{n}\right\|=0
$$

for every $y_{2}, \ldots, y_{n} \in X$. Every convergent sequence has exactly one limit. If $x$ is the limit of the sequence $\left\{x_{j}\right\}_{j \in \mathbb{N}}$, then we write $\lim _{j \rightarrow \infty} x_{j}=x$. For any convergent sequences $\left\{x_{j}\right\}_{j \in \mathbb{N}}$ and $\left\{y_{j}\right\}_{j \in \mathbb{N}}$ of elements of $X$, the sequence $\left\{x_{j}+y_{j}\right\}_{j \in \mathbb{N}}$ is convergent and

$$
\lim _{j \rightarrow \infty}\left(x_{j}+y_{j}\right)=\lim _{j \rightarrow \infty} x_{j}+\lim _{j \rightarrow \infty} y_{j} .
$$

If, moreover, $\left\{\alpha_{j}\right\}_{j \in \mathbb{N}}$ is a convergent sequence of real numbers, then the sequence $\left\{\alpha_{j} \cdot x_{j}\right\}_{j \in \mathbb{N}}$ is also convergent and

$$
\lim _{j \rightarrow \infty}\left(\alpha_{j} \cdot x_{j}\right)=\lim _{j \rightarrow \infty} \alpha_{j} \cdot \lim _{j \rightarrow \infty} x_{j} .
$$


A sequence $\left\{x_{j}\right\}_{j \in \mathbb{N}}$ in an $n$-normed space $X$ is said to be a Cauchy sequence with respect to the $n$-norm if

$$
\lim _{j, l \rightarrow \infty}\left\|x_{j}-x_{l}, y_{2}, \ldots, y_{n}\right\|=0
$$

for every $y_{2}, \ldots, y_{n} \in X$. A linear $n$-normed space in which every Cauchy sequence is convergent is called an $n$-Banach space.

Example 2. For $x_{1}, \ldots, x_{n} \in \mathbb{R}^{n}$, the Euclidean $n$-norm $\| x_{1}$, $\ldots, x_{n} \|_{E}$ is defined by

$$
\left\|x_{1}, \ldots, x_{n}\right\|_{E}=\left|\operatorname{det}\left(x_{i j}\right)\right|=\operatorname{abs}\left(\left|\begin{array}{ccc}
x_{11} & \cdots & x_{1 n} \\
\vdots & \ddots & \vdots \\
x_{n 1} & \cdots & x_{n n}
\end{array}\right|\right) \text {, }
$$

where $x_{i}=\left(x_{i 1}, \ldots, x_{i n}\right) \in \mathbb{R}^{n}$ for each $i=1, \ldots, n$.

Example 3. The standard $n$-norm on $X$, a real inner product space of dimension $\operatorname{dim} X \geq n$, is as follows:

$$
\left\|x_{1}, \ldots, x_{n}\right\|_{S}=\left|\begin{array}{ccc}
\left\langle x_{1}, x_{1}\right\rangle & \cdots & \left\langle x_{1}, x_{n}\right\rangle \\
\vdots & \ddots & \vdots \\
\left\langle x_{n}, x_{1}\right\rangle & \cdots & \left\langle x_{n}, x_{n}\right\rangle
\end{array}\right|^{1 / 2}
$$

where $\langle\cdot, \cdot\rangle$ denotes the inner product on $X$. If $X=\mathbb{R}^{n}$, then this $n$-norm is exactly the same as the Euclidean $n$-norm $\left\|x_{1}, \ldots, x_{n}\right\|_{E}$ mentioned earlier. For $n=1$, this $n$-norm is the usual norm $\left\|x_{1}\right\|=\left\langle x_{1}, x_{1}\right\rangle^{1 / 2}$.

In what follows, we will also use the following lemma from [19].

Lemma 4. Let $X$ be an n-normed space. Then,

(1) for $x_{i} \in X(i=1, \ldots, n)$ and $\gamma$, a real number,

$$
\begin{aligned}
& \left\|x_{1}, \ldots, x_{i}, \ldots, x_{j}, \ldots, x_{n}\right\| \\
& \quad=\left\|x_{1}, \ldots, x_{i}, \ldots, x_{j}+\gamma x_{i}, \ldots, x_{n}\right\|,
\end{aligned}
$$

for all $1 \leq i \neq j \leq n$,

(2) $\left|\left\|x, y_{2}, \ldots, y_{n}\right\|-\left\|y, y_{2}, \ldots, y_{n}\right\|\right| \leq\left\|x-y, y_{2}, \ldots, y_{n}\right\|$ for all $x, y, y_{2}, \ldots, y_{n} \in X$,

(3) if $\left\|x, y_{2}, \ldots, y_{n}\right\|=0$ for all $y_{2}, \ldots, y_{n} \in X$, then $x=0$,

(4) for a convergent sequence $\left\{x_{j}\right\}$ in $X$,

$$
\lim _{j \rightarrow \infty}\left\|x_{j}, y_{2}, \ldots, y_{n}\right\|=\left\|\lim _{j \rightarrow \infty} x_{j}, y_{2}, \ldots, y_{n}\right\|,
$$

for all $y_{2}, \ldots, y_{n} \in X$.

\section{Approximate Multi-Jensen Mappings}

First, we prove the stability of the system of equations defining multi-Jensen mappings in $n$-Banach spaces. For a given mapping $f: V^{k} \rightarrow W$, we define the difference operators

$$
\begin{aligned}
D_{i} f\left(x_{1}, \ldots, x_{k+1}\right) & :=2 f\left(x_{1}, \ldots, x_{i-1}, \frac{x_{i}+x_{i+1}}{2}, x_{i+2}, \ldots, x_{k+1}\right) \\
& -f\left(x_{1}, \ldots, x_{i}, x_{i+2}, \ldots, x_{k+1}\right) \\
& -f\left(x_{1}, \ldots, x_{i-1}, x_{i+1}, \ldots, x_{k+1}\right), \\
& \left(x_{1}, \ldots, x_{k+1}\right) \in V^{k+1}, \quad i \in\{1, \ldots, k\} .
\end{aligned}
$$

Theorem 5. Let $V$ be a commutative group uniquely divisible by 2 , and, $W$ be an $n$-Banach space. Assume also that for every $i \in\{1, \ldots, k\}, \varphi_{i}: V^{k+1} \rightarrow[0, \infty)$ is a mapping such that

$$
\begin{aligned}
& \sum_{j=0}^{\infty} \frac{1}{3^{j+1}}[ \varphi_{i}\left(3^{j} x_{1}, x_{2}, \ldots, x_{k+1}\right) \\
&+\cdots+\varphi_{i}\left(x_{1}, \ldots, x_{i-2}, 3^{j} x_{i-1}, x_{i}, \ldots, x_{k+1}\right) \\
&+\varphi_{i}\left(x_{1}, \ldots, x_{i-1}, 3^{j} x_{i}, 3^{j} x_{i+1}, x_{i+2}, \ldots, x_{k+1}\right) \\
&+\varphi_{i}\left(x_{1}, \ldots, x_{i+1}, 3^{j} x_{i+2}, x_{i+3}, \ldots, x_{k+1}\right) \\
&\left.+\cdots+\varphi_{i}\left(x_{1}, \ldots, x_{k}, 3^{j} x_{k+1}\right)\right]<\infty \\
&\left(x_{1}, \ldots, x_{k+1}\right) \in V^{k+1}
\end{aligned}
$$

If $f: V^{k} \rightarrow W$ is a function satisfying

$$
f\left(x_{1}, \ldots, x_{i-1}, 0, x_{i+1}, \ldots, x_{k}\right)=0,
$$

$$
\begin{gathered}
\left(x_{1}, \ldots, x_{i-1}, x_{i+1}, \ldots, x_{k}\right) \in V^{k-1}, \quad i \in\{1, \ldots, k\}, \\
\left\|D_{i} f\left(x_{1}, \ldots, x_{k+1}\right), y_{2}, \ldots, y_{n}\right\| \leq \varphi_{i}\left(x_{1}, \ldots, x_{k+1}\right), \\
\left(x_{1}, \ldots, x_{k+1}\right) \in V^{k+1}, \quad i \in\{1, \ldots, k\}, \quad y_{2}, \ldots, y_{n} \in W,
\end{gathered}
$$

then for every $i \in\{1, \ldots, k\}$, there exists a multi-Jensen mapping $F_{i}: V^{k} \rightarrow W$ for which

$$
\begin{aligned}
& \left\|f\left(x_{1}, \ldots, x_{k}\right)-F_{i}\left(x_{1}, \ldots, x_{k}\right), y_{2}, \ldots, y_{n}\right\| \\
& \leq \sum_{j=0}^{\infty} \frac{1}{3^{j+1}} \\
& \quad \times\left[\varphi_{i}\left(x_{1}, \ldots, x_{i-1}, 3^{j} x_{i},-3^{j} x_{i}, x_{i+1}, \ldots, x_{k}\right)\right. \\
& \left.+\varphi_{i}\left(x_{1}, \ldots, x_{i-1},-3^{j} x_{i}, 3^{j+1} x_{i}, x_{i+1}, \ldots, x_{k}\right)\right], \\
& \left(x_{1}, \ldots, x_{k}\right) \in V^{k}, \quad y_{2}, \ldots, y_{n} \in W .
\end{aligned}
$$


For every $i \in\{1, \ldots, k\}$, the function $F_{i}$ is given by

$$
F_{i}\left(x_{1}, \ldots, x_{k}\right):=\lim _{j \rightarrow \infty} \frac{1}{3^{j}} f\left(x_{1}, \ldots, x_{i-1}, 3^{j} x_{i}, x_{i+1}, \ldots, x_{k}\right),
$$

$$
\left(x_{1}, \ldots, x_{k}\right) \in V^{k}
$$

Proof. Fix $x_{1}, \ldots, x_{k} \in V, y_{2}, \ldots, y_{n} \in W$ and $i \in\{1, \ldots, k\}$. By (12) and (11), we get

$$
\begin{aligned}
& \| f\left(x_{1}, \ldots, x_{k}\right)+f\left(x_{1}, \ldots, x_{i-1},-x_{i}, x_{i+1}, \ldots, x_{k}\right), \\
& y_{2}, \ldots, y_{n} \| \\
& \quad \leq \varphi_{i}\left(x_{1}, \ldots, x_{i},-x_{i}, x_{i+1}, \ldots, x_{k}\right), \\
& \| 2 f\left(x_{1}, \ldots, x_{k}\right)-f\left(x_{1}, \ldots, x_{i-1},-x_{i}, x_{i+1}, \ldots, x_{k}\right) \\
& -f\left(x_{1}, \ldots, x_{i-1}, 3 x_{i}, x_{i+1}, \ldots, x_{k}\right), y_{2}, \ldots, y_{n} \| \\
& \quad \leq \varphi_{i}\left(x_{1}, \ldots, x_{i-1},-x_{i}, 3 x_{i}, x_{i+1}, \ldots, x_{k}\right) .
\end{aligned}
$$

Hence,

$$
\begin{aligned}
& \| 3 f\left(x_{1}, \ldots, x_{k}\right)-f\left(x_{1}, \ldots, x_{i-1}, 3 x_{i}, x_{i+1}, \ldots, x_{k}\right), \\
& y_{2}, \ldots, y_{n} \| \\
& \leq \varphi_{i}\left(x_{1}, \ldots, x_{i},-x_{i}, x_{i+1}, \ldots, x_{k}\right) \\
& \quad+\varphi_{i}\left(x_{1}, \ldots, x_{i-1},-x_{i}, 3 x_{i}, x_{i+1}, \ldots, x_{k}\right),
\end{aligned}
$$

and consequently for any nonnegative integers $l$ and $m$ such that $l<m$, we obtain

$$
\begin{aligned}
& \| \frac{1}{3^{l}} f\left(x_{1}, \ldots, x_{i-1}, 3^{l} x_{i}, x_{i+1}, \ldots, x_{k}\right) \\
& -\frac{1}{3^{m}} f\left(x_{1}, \ldots, x_{i-1}, 3^{m} x_{i}, x_{i+1}, \ldots, x_{k}\right), y_{2}, \ldots, y_{n} \| \\
& \leq \sum_{j=l}^{m-1} \frac{1}{3^{j+1}}\left[\varphi_{i}\left(x_{1}, \ldots, x_{i-1}, 3^{j} x_{i},-3^{j} x_{i}, x_{i+1}, \ldots, x_{k}\right)\right. \\
& \left.\quad+\varphi_{i}\left(x_{1}, \ldots, x_{i-1},-3^{j} x_{i}, 3^{j+1} x_{i}, x_{i+1}, \ldots, x_{k}\right)\right] .
\end{aligned}
$$

Therefore, from (10), it follows that $\left\{\left(1 / 3^{j}\right) f\left(x_{1}, \ldots, x_{i-1}\right.\right.$, $\left.\left.3^{j} x_{i}, x_{i+1}, \ldots, x_{k}\right)\right\}_{j \in \mathbb{N}}$ is a Cauchy sequence. Since $W$ is an $n$-Banach space, this sequence is convergent and we define $F_{i}: V^{k} \rightarrow W$ by (14). Putting $l=0$, letting $m \rightarrow \infty$ in (17), and using Lemma 4 and (10), we see that (13) holds.

Finally, fix $x_{i}^{\prime} \in V, j \in \mathbb{N}$, and note that according to (12), we have

$$
\begin{gathered}
\left\|\frac{1}{3^{j}} D_{i} f\left(x_{1}, \ldots, x_{i-1}, 3^{j} x_{i}, 3^{j} x_{i}^{\prime}, x_{i+1}, \ldots, x_{k}\right), y_{2}, \ldots, y_{n}\right\| \\
\leq \frac{1}{3^{j}} \varphi_{i}\left(x_{1}, \ldots, x_{i-1}, 3^{j} x_{i}, 3^{j} x_{i}^{\prime}, x_{i+1}, \ldots, x_{k}\right) .
\end{gathered}
$$

Next, fix $s \in\{1, \ldots, k\} \backslash\{i\}, x_{s}^{\prime} \in V$, and assume that $s<i$ (the same arguments apply to the case where $s>i$ ). From (12), it follows that

$$
\begin{gathered}
\| \frac{1}{3^{j}} D_{s} f\left(x_{1}, \ldots, x_{s}, x_{s}^{\prime}, x_{s+1}, \ldots, x_{i-1},\right. \\
\left.3^{j} x_{i}, x_{i+1}, \ldots, x_{k}\right), y_{2}, \ldots, y_{n} \| \\
\leq \frac{1}{3^{j}} \varphi_{s}\left(x_{1}, \ldots, x_{s}, x_{s}^{\prime}, x_{s+1}, \ldots,\right. \\
\left.x_{i-1}, 3^{j} x_{i}, x_{i+1}, \ldots, x_{k}\right) .
\end{gathered}
$$

Letting $j \rightarrow \infty$ in the above two inequalities and using (10) and Lemma 4 , we see that the mapping $F_{i}$ is multi-Jensen.

Theorem 6. Let $V$ be a real linear space and, $W$ be an $n$ Banach space. Assume also that for every $i \in\{1, \ldots, k\}, \varphi_{i}$ : $V^{k+1} \rightarrow[0, \infty)$ is a mapping such that

$$
\begin{aligned}
& \sum_{j=0}^{\infty} 3^{j}[ \varphi_{i}\left(\frac{x_{1}}{3^{j}}, x_{2}, \ldots, x_{k+1}\right) \\
&+\cdots+\varphi_{i}\left(x_{1}, \ldots, x_{i-2}, \frac{x_{i-1}}{3^{j}}, x_{i}, \ldots, x_{k+1}\right) \\
&+\varphi_{i}\left(x_{1}, \ldots, x_{i-1}, \frac{x_{i}}{3^{j}}, \frac{x_{i+1}}{3^{j}}, x_{i+2}, \ldots, x_{k+1}\right) \\
&+\varphi_{i}\left(x_{1}, \ldots, x_{i+1}, \frac{x_{i+2}}{3^{j}}, x_{i+3}, \ldots, x_{k+1}\right) \\
&\left.+\cdots+\varphi_{i}\left(x_{1}, \ldots, x_{k}, \frac{x_{k+1}}{3^{j}}\right)\right]<\infty \\
& \quad\left(x_{1}, \ldots, x_{k+1}\right) \in V^{k+1}
\end{aligned}
$$

If $f: V^{k} \rightarrow W$ is a function satisfying conditions (11) and (12), then for every $i \in\{1, \ldots, k\}$ there exists a multi-Jensen mapping $F_{i}: V^{k} \rightarrow W$ for which

$$
\begin{array}{r}
\left\|f\left(x_{1}, \ldots, x_{k}\right)-F_{i}\left(x_{1}, \ldots, x_{k}\right), y_{2}, \ldots, y_{n}\right\| \\
\leq \sum_{j=0}^{\infty} 3^{j}\left[\varphi_{i}\left(x_{1}, \ldots, x_{i-1}, \frac{x_{i}}{3^{j+1}},-\frac{x_{i}}{3^{j+1}}, x_{i+1}, \ldots, x_{k}\right)\right. \\
\left.+\varphi_{i}\left(x_{1}, \ldots, x_{i-1},-\frac{x_{i}}{3^{j+1}}, \frac{x_{i}}{3^{j}}, x_{i+1}, \ldots, x_{k}\right)\right], \\
\left(x_{1}, \ldots, x_{k}\right) \in V^{k}, y_{2}, \ldots, y_{n} \in W .
\end{array}
$$

For every $i \in\{1, \ldots, k\}$, the function $F_{i}$ is given by

$$
\begin{aligned}
& F_{i}\left(x_{1}, \ldots, x_{k}\right) \\
& \quad:=\lim _{j \rightarrow \infty} 3^{j} f\left(x_{1}, \ldots, x_{i-1}, \frac{x_{i}}{3^{j}}, x_{i+1}, \ldots, x_{k}\right),
\end{aligned}
$$

$$
\left(x_{1}, \ldots, x_{k}\right) \in V^{k}
$$


Proof. Fix $x_{1}, \ldots, x_{k} \in V, y_{2}, \ldots, y_{n} \in W, j \in \mathbb{N} \cup\{0\}$ and $i \in$ $\{1, \ldots, k\}$. By (12) and (11), we get

$$
\begin{aligned}
& \| 3^{j+1} f\left(x_{1}, \ldots, x_{i-1}, \frac{x_{i}}{3^{j+1}}, x_{i+1}, \ldots, x_{k}\right) \\
& -3^{j} f\left(x_{1}, \ldots, x_{i-1}, \frac{x_{i}}{3^{j}}, x_{i+1}, \ldots, x_{k}\right), y_{2}, \ldots, y_{n} \| \\
& \leq 3^{j}\left[\varphi_{i}\left(x_{1}, \ldots, x_{i-1}, \frac{x_{i}}{3^{j+1}},-\frac{x_{i}}{3^{j+1}}, x_{i+1}, \ldots, x_{k}\right)\right. \\
& \left.\quad+\varphi_{i}\left(x_{1}, \ldots, x_{i-1},-\frac{x_{i}}{3^{j+1}}, \frac{x_{i}}{3^{j}}, x_{i+1}, \ldots, x_{k}\right)\right],
\end{aligned}
$$

and consequently for any non-negative integers $l$ and $m$ such that $l<m$, we obtain

$$
\begin{array}{r}
\| 3^{l} f\left(x_{1}, \ldots, x_{i-1}, \frac{x_{i}}{3^{l}}, x_{i+1}, \ldots, x_{k}\right) \\
-3^{m} f\left(x_{1}, \ldots, x_{i-1}, \frac{x_{i}}{3^{m}}, x_{i+1}, \ldots, x_{k}\right), y_{2}, \ldots, y_{n} \| \\
\leq \sum_{j=l}^{m-1} 3^{j}\left[\varphi_{i}\left(x_{1}, \ldots, x_{i-1}, \frac{x_{i}}{3^{j+1}},-\frac{x_{i}}{3^{j+1}}, x_{i+1}, \ldots, x_{k}\right)\right. \\
\left.+\varphi_{i}\left(x_{1}, \ldots, x_{i-1},-\frac{x_{i}}{3^{j+1}}, \frac{x_{i}}{3^{j}}, x_{i+1}, \ldots, x_{k}\right)\right] .
\end{array}
$$

Therefore, from (20), it follows that $\left\{3^{j} f\left(x_{1}, \ldots, x_{i-1}, x_{i} / 3^{j}\right.\right.$, $\left.\left.x_{i+1}, \ldots, x_{k}\right)\right\}_{j \in \mathbb{N}}$ is a Cauchy sequence. Since $W$ is an $n$ Banach space, this sequence is convergent and we define $F_{i}$ : $V^{k} \rightarrow W$ by (22). Putting $l=0$, letting $m \rightarrow \infty$ in (24), and using Lemma 4 and (20), we see that (21) holds.

Finally, fix $x_{i}^{\prime} \in V$, and note that according to (12), we have

$$
\begin{gathered}
\left\|3^{j} D_{i} f\left(x_{1}, \ldots, x_{i-1}, \frac{x_{i}}{3^{j}}, \frac{x_{i}^{\prime}}{3^{j}}, x_{i+1}, \ldots, x_{k}\right), y_{2}, \ldots, y_{n}\right\| \\
\quad \leq 3^{j} \varphi_{i}\left(x_{1}, \ldots, x_{i-1}, \frac{x_{i}}{3^{j}}, \frac{x_{i}^{\prime}}{3^{j}}, x_{i+1}, \ldots, x_{k}\right) .
\end{gathered}
$$

Next, fix $s \in\{1, \ldots, k\} \backslash\{i\}, x_{s}^{\prime} \in V$, and assume that $s<i$ (the same arguments apply to the case where $s>i$ ). From (12), it follows that

$$
\begin{aligned}
& \| 3^{j} D_{s} f\left(x_{1}, \ldots, x_{s}, x_{s}^{\prime}, x_{s+1}, \ldots, x_{i-1}, \frac{x_{i}}{3^{j}}, x_{i+1}, \ldots, x_{k}\right), \\
& y_{2}, \ldots, y_{n} \| \\
& \quad \leq 3^{j} \varphi_{s}\left(x_{1}, \ldots, x_{s}, x_{s}^{\prime}, x_{s+1}, \ldots, x_{i-1}, \frac{x_{i}}{3^{j}}, x_{i+1}, \ldots, x_{k}\right) .
\end{aligned}
$$

Letting $j \rightarrow \infty$ in the previous two inequalities and using (20) and Lemma 4 , we see that the mapping $F_{i}$ is multiJensen.

As applications of Theorems 5 and 6 we get the following corollaries.
Corollary 7. Let $V$ be a real normed linear space and, $W$ be an $n$-Banach space. Assume also that $\theta \in[0, \infty)$ and $r \in(0, \infty)$ are such that $r \neq 1$. If $f: V^{k} \rightarrow W$ is a function satisfying (11) and

$$
\begin{array}{r}
\left\|D_{i} f\left(x_{1}, \ldots, x_{k+1}\right), y_{2}, \ldots, y_{n}\right\| \\
\leq \theta\left[\left\|x_{1}\right\|^{r} \cdots\left\|x_{i-1}\right\|^{r}\left(\left\|x_{i}\right\|^{r}+\left\|x_{i+1}\right\|^{r}\right)\right. \\
\left.\times\left\|x_{i+2}\right\|^{r} \cdots\left\|x_{k+1}\right\|^{r}\right], \\
\left(x_{1}, \ldots, x_{k+1}\right) \in V^{k+1}, \quad i \in\{1, \ldots, k\}, \\
y_{2}, \ldots, y_{n} \in W,
\end{array}
$$

then for every $i \in\{1, \ldots, k\}$ there exists a multi-Jensen mapping $F_{i}: V^{k} \rightarrow W$ for which

$$
\begin{aligned}
& \left\|f\left(x_{1}, \ldots, x_{k}\right)-F_{i}\left(x_{1}, \ldots, x_{k}\right), y_{2}, \ldots, y_{n}\right\| \\
& \quad \leq \frac{\theta\left\|x_{1}\right\|^{r} \cdots\left\|x_{k}\right\|^{r}\left(3+3^{r}\right)}{\left|3-3^{r}\right|},
\end{aligned}
$$

for all $x_{1}, \ldots, x_{k} \in V, y_{2}, \ldots, y_{n} \in W$.

Corollary 8. Let $V$ be a real normed linear space and let $W$ be an $n$-Banach space. Assume also that $\theta \in[0, \infty)$ and $r, p, q \in$ $(0, \infty)$ are such that $r, p+q \in(0,1)$ or $r, p+q \in(1, \infty)$. If $f: V^{k} \rightarrow W$ is a function satisfying (11) and

$$
\begin{aligned}
\left\|D_{i} f\left(x_{1}, \ldots, x_{k+1}\right), y_{2}, \ldots, y_{n}\right\| & \\
\leq & \theta\left\|x_{1}\right\|^{r} \cdots\left\|x_{i-1}\right\|^{r}\left(\left\|x_{i}\right\|^{p}\left\|x_{i+1}\right\|^{q}\right) \\
& \times\left\|x_{i+2}\right\|^{r} \cdots\left\|x_{k+1}\right\|^{r}, \\
& \left(x_{1}, \ldots, x_{k+1}\right) \in V^{k+1}, \quad i \in\{1, \ldots, k\}, \\
& y_{2}, \ldots, y_{n} \in W,
\end{aligned}
$$

then for every $i \in\{1, \ldots, k\}$, there exists a multi-Jensen mapping $F_{i}: V^{k} \rightarrow W$ for which

$$
\begin{aligned}
& \left\|f\left(x_{1}, \ldots, x_{k}\right)-F_{i}\left(x_{1}, \ldots, x_{k}\right), y_{2}, \ldots, y_{n}\right\| \\
& \quad \leq \frac{\theta\left\|x_{1}\right\|^{r} \cdots\left\|x_{i-1}\right\|^{r}\left\|x_{i}\right\|^{p+q}\left\|x_{i+1}\right\|^{r} \cdots\left\|x_{k}\right\|^{r}\left(1+3^{q}\right)}{\left|3-3^{p+q}\right|},
\end{aligned}
$$

for all $x_{1}, \ldots, x_{k} \in V, y_{2}, \ldots, y_{n} \in W$.

From Corollary 8, we obtain the following corollary which corrects Theorems 3.1 and 3.2 from [20].

Corollary 9. Let $V$ be a real normed linear space and $W$ be an $n$-Banach space. Assume also that $\theta \in[0, \infty)$ and $p, q \in$ $(0, \infty)$ are such that $p+q \neq 1$. If $f: V \rightarrow W$ is a function satisfying $f(0)=0$ and

$$
\begin{aligned}
& \left\|2 f\left(\frac{x_{1}+x_{2}}{2}\right)-f\left(x_{1}\right)-f\left(x_{2}\right), y\right\| \\
& \quad \leq \theta\left\|x_{1}\right\|^{p}\left\|x_{2}\right\|^{q}, \quad x_{1}, x_{2} \in V, y \in W,
\end{aligned}
$$


then there exists a Jensen mapping $F: V \rightarrow W$ for which

$$
\begin{aligned}
& \|f(x)-F(x), y\| \\
& \leq \frac{\theta\|x\|^{p+q}\left(1+3^{q}\right)}{\left|3-3^{p+q}\right|}, \quad x \in V, \quad y \in W .
\end{aligned}
$$

\section{Approximate Multi-Euler-Lagrange Additive Mappings}

In this section, we prove the stability of the system of equations defining multi-Euler-Lagrange additive mappings.

Throughout this section, let $V$ be a real linear space and let $W$ be an $n$-Banach space, and $a, b \in \mathbb{R} \backslash\{0\}$ are fixed with $\lambda:=a+b \neq 0, \pm 1$.

A mapping $f: V^{k} \rightarrow W$ is called a multiEuler-Lagrange additive mapping as follows if it satisfies the Euler-Lagrange additive equations in each of their $k$ arguments as follows:

$$
\begin{aligned}
& f\left(x_{1}, \ldots, x_{i-1}, a x_{i}+b x_{i}^{\prime}, x_{i+1}, \ldots, x_{k}\right) \\
& +f\left(x_{1}, \ldots, x_{i-1}, b x_{i}+a x_{i}^{\prime}, x_{i+1}, \ldots, x_{k}\right) \\
& =(a+b)\left[f\left(x_{1}, \ldots, x_{k}\right)\right. \\
& \left.+f\left(x_{1}, \ldots, x_{i-1}, x_{i}^{\prime}, x_{i+1}, \ldots, x_{k}\right)\right],
\end{aligned}
$$

for all $i \in\{1, \ldots, k\}$ and all $x_{1}, \ldots, x_{i-1}, x_{i}, x_{i}^{\prime}, x_{i+1}, \ldots, x_{k} \in$ $V$. If $a=b=1$, then the multi-Euler-Lagrange additive mapping is multiadditive (see [28]). For a given mapping $f$ : $V^{k} \rightarrow W$, we define the difference operators

$$
\begin{aligned}
\widetilde{D}_{i} f\left(x_{1}, \ldots, x_{k+1}\right) & \\
:= & f\left(x_{1}, \ldots, x_{i-1}, a x_{i}+b x_{i+1}, x_{i+2}, \ldots, x_{k+1}\right) \\
& +f\left(x_{1}, \ldots, x_{i-1}, b x_{i}+a x_{i+1}, x_{i+2}, \ldots, x_{k+1}\right) \\
-(a+b)[ & f\left(x_{1}, \ldots, x_{i}, x_{i+2}, \ldots, x_{k+1}\right) \\
& \left.+f\left(x_{1}, \ldots, x_{i-1}, x_{i+1}, \ldots, x_{k+1}\right)\right], \\
& \left(x_{1}, \ldots, x_{k+1}\right) \in V^{\mathrm{k}+1}, \quad i \in\{1, \ldots, k\} .
\end{aligned}
$$

Theorem 10. Assume that for every $i \in\{1, \ldots, k\}, \varphi_{i}$ : $V^{k+1} \rightarrow[0, \infty)$ is a mapping such that

$$
\begin{aligned}
& \sum_{j=0}^{\infty} \frac{1}{|\lambda|^{j}}[ \varphi_{i}\left(\lambda^{j} x_{1}, \ldots, x_{k+1}\right) \\
&+\cdots+\varphi_{i}\left(x_{1}, \ldots, x_{i-2}, \lambda^{j} x_{i-1}, x_{i}, \ldots, x_{k+1}\right) \\
&+\varphi_{i}\left(x_{1}, \ldots, x_{i-1}, \lambda^{j} x_{i}, \lambda^{j} x_{i+1}, x_{i+2}, \ldots, x_{k+1}\right) \\
&+\varphi_{i}\left(x_{1}, \ldots, x_{i+1}, \lambda^{j} x_{i+2}, x_{i+3}, \ldots, x_{k+1}\right) \\
&\left.+\cdots+\varphi_{i}\left(x_{1}, \ldots, x_{k}, \lambda^{j} x_{k+1}\right)\right]<\infty \\
&\left(x_{1}, \ldots, x_{k+1}\right) \in V^{k+1}
\end{aligned}
$$

If $f: V^{k} \rightarrow W$ is a function satisfying

$$
\begin{array}{r}
\left\|\widetilde{D}_{i} f\left(x_{1}, \ldots, x_{k+1}\right), y_{2}, \ldots, y_{n}\right\| \leq \varphi_{i}\left(x_{1}, \ldots, x_{k+1}\right), \\
\left(x_{1}, \ldots, x_{k+1}\right) \in V^{k+1}, \quad i \in\{1, \ldots, k\}, \quad y_{2}, \ldots, y_{n} \in W,
\end{array}
$$

then for every $i \in\{1, \ldots, k\}$, there exists a unique multi-EulerLagrange additive mapping $A_{i}: V^{k} \rightarrow W$ for which

$$
\begin{aligned}
& \left\|f\left(x_{1}, \ldots, x_{k}\right)-A_{i}\left(x_{1}, \ldots, x_{k}\right), y_{2}, \ldots, y_{n}\right\| \\
& \leq \frac{1}{2} \sum_{j=0}^{\infty} \frac{1}{|\lambda|^{j+1}} \\
& \quad \times \varphi_{i}\left(x_{1}, \ldots, x_{i-1}, \lambda^{j} x_{i}, \lambda^{j} x_{i}, x_{i+1}, \ldots, x_{k}\right), \\
& \quad\left(x_{1}, \ldots, x_{k}\right) \in V^{k}, \quad y_{2}, \ldots, y_{n} \in W .
\end{aligned}
$$

For every $i \in\{1, \ldots, k\}$, the function $A_{i}$ is given by

$$
\begin{array}{r}
A_{i}\left(x_{1}, \ldots, x_{k}\right) \\
\quad:=\lim _{j \rightarrow \infty} \frac{1}{\lambda^{j}} f\left(x_{1}, \ldots, x_{i-1}, \lambda^{j} x_{i}, x_{i+1}, \ldots, x_{k}\right), \\
\left(x_{1}, \ldots, x_{k}\right) \in V^{k} .
\end{array}
$$

Proof. Fix $x_{1}, \ldots, x_{k} \in V, y_{2}, \ldots, y_{n} \in W, j \in \mathbb{N} \cup\{0\}$ and $i \in$ $\{1, \ldots, k\}$. By (36), we get

$$
\begin{aligned}
& \| f\left(x_{1}, \ldots, x_{k}\right)-\frac{1}{\lambda} f\left(x_{1}, \ldots, x_{i-1}, \lambda x_{i}, x_{i+1}, \ldots, x_{k}\right), \\
& y_{2}, \ldots, y_{n} \| \\
& \leq \frac{1}{|2 \lambda|} \varphi_{i}\left(x_{1}, \ldots, x_{i}, x_{i}, x_{i+1}, \ldots, x_{k}\right),
\end{aligned}
$$

whence

$$
\begin{aligned}
& \| \frac{1}{\lambda^{j}} f\left(x_{1}, \ldots, x_{i-1}, \lambda^{j} x_{i}, x_{i+1}, \ldots, x_{k}\right) \\
& -\frac{1}{\lambda^{j+1}} f\left(x_{1}, \ldots, x_{i-1}, \lambda^{j+1} x_{i}, x_{i+1}, \ldots, x_{k}\right), y_{2}, \ldots, y_{n} \| \\
& \quad \leq \frac{1}{2|\lambda|^{j+1}} \varphi_{i}\left(x_{1}, \ldots, x_{i-1}, \lambda^{j} x_{i}, \lambda^{j} x_{i}, x_{i+1}, \ldots, x_{k}\right) .
\end{aligned}
$$

For any nonnegative integers $l$ and $m$ with $l<m$, using (40) we get

$$
\begin{aligned}
& \| \frac{1}{\lambda^{l}} f\left(x_{1}, \ldots, x_{i-1}, \lambda^{l} x_{i}, x_{i+1}, \ldots, x_{k}\right) \\
& -\frac{1}{\lambda^{m}} f\left(x_{1}, \ldots, x_{i-1}, \lambda^{m} x_{i}, x_{i+1}, \ldots, x_{k}\right), y_{2}, \ldots, y_{n} \| \\
& \leq \sum_{j=l}^{m-1} \frac{1}{2|\lambda|^{j+1}} \\
& \quad \times \varphi_{i}\left(x_{1}, \ldots, x_{i-1}, \lambda^{j} x_{i}, \lambda^{j} x_{i}, x_{i+1}, \ldots, x_{k}\right),
\end{aligned}
$$


which tends to zero as $l$ tends to infinity. Therefore, from (35) it follows that $\left\{\left(1 / \lambda^{j}\right) f\left(x_{1}, \ldots, x_{i-1}, \lambda^{j} x_{i}, x_{i+1}, \ldots, x_{k}\right)\right\}_{j \in \mathbb{N}}$ is a Cauchy sequence in $n$-Banach space $W$ and it thus converges. Hence, we can define $A_{i}: V^{k} \rightarrow W$ by

$$
\begin{aligned}
& A_{i}\left(x_{1}, \ldots, x_{k}\right) \\
& \quad:=\lim _{j \rightarrow \infty} \frac{1}{\lambda^{j}} f\left(x_{1}, \ldots, x_{i-1}, \lambda^{j} x_{i}, x_{i+1}, \ldots, x_{k}\right) .
\end{aligned}
$$

Putting $l=0$, letting $m \rightarrow \infty$ in (41), and using (35), we see that (37) holds.

Now, fix also $x_{i}^{\prime} \in V$, and from (36), we have

$$
\begin{aligned}
& \| \frac{1}{\lambda^{j}} \widetilde{D}_{i} f\left(x_{1}, \ldots, x_{i-1}, \lambda^{j} x_{i}, \lambda^{j} x_{i}^{\prime}, x_{i+1}, \ldots, x_{k}\right), \\
& \quad y_{2}, \ldots, y_{n} \| \\
& \quad \leq \frac{1}{|\lambda|^{j}} \varphi_{i}\left(x_{1}, \ldots, x_{i-1}, \lambda^{j} x_{i}, \lambda^{j} x_{i}^{\prime}, x_{i+1}, \ldots, x_{k}\right) .
\end{aligned}
$$

Next, fix $s \in\{1, \ldots, k\} \backslash\{i\}, x_{s}^{\prime} \in V$, and assume that $s<i$ (the same arguments apply to the case where $s>i$ ). From (36) it follows that

$$
\begin{gathered}
\| \frac{1}{\lambda^{j}} \widetilde{D}_{s} f\left(x_{1}, \ldots, x_{s}, x_{s}^{\prime}, x_{s+1}, \ldots, x_{i-1},\right. \\
\left.\lambda^{j} x_{i}, x_{i+1}, \ldots, x_{k}\right), y_{2}, \ldots, y_{n} \| \\
\leq \frac{1}{|\lambda|^{j}} \varphi_{s}\left(x_{1}, \ldots, x_{s}, x_{s}^{\prime}, x_{s+1}, \ldots, x_{i-1},\right. \\
\left.\lambda^{j} x_{i}, x_{i+1}, \ldots, x_{k}\right) .
\end{gathered}
$$

Letting $j \rightarrow \infty$ in the above two inequalities and using (35) and Lemma 4 , we see that the mapping $A_{i}$ is multi-EulerLagrange additive.

Now, let us finally assume that $A_{i}^{\prime}: V^{k} \rightarrow W$ is another multi-Euler-Lagrange additive mapping satisfying (37). Then we have

$$
\begin{aligned}
& \left\|A_{i}\left(x_{1}, \ldots, x_{k}\right)-A_{i}^{\prime}\left(x_{1}, \ldots, x_{k}\right), y_{2}, \ldots, y_{n}\right\| \\
& =\lim _{m \rightarrow \infty} \frac{1}{|\lambda|^{m}} \\
& \quad \times \| A_{i}\left(x_{1}, \ldots, x_{i-1}, \lambda^{m} x_{i}, x_{i+1}, \ldots, x_{k}\right) \\
& \quad-A_{i}^{\prime}\left(x_{1}, \ldots, x_{i-1}, \lambda^{m} x_{i}, x_{i+1}, \ldots, x_{k}\right), y_{2}, \ldots, y_{n} \|
\end{aligned}
$$

$$
\begin{aligned}
& \leq \lim _{m \rightarrow \infty} \frac{1}{|\lambda|^{m}} \\
& \times\left[\| A_{i}\left(x_{1}, \ldots, x_{i-1}, \lambda^{m} x_{i}, x_{i+1}, \ldots, x_{k}\right)\right. \\
& \quad-f\left(x_{1}, \ldots, x_{i-1}, \lambda^{m} x_{i}, x_{i+1}, \ldots, x_{k}\right), y_{2}, \ldots, y_{n} \| \\
& \quad+\| f\left(x_{1}, \ldots, x_{i-1}, \lambda^{m} x_{i}, x_{i+1}, \ldots, x_{k}\right) \\
&\left.\quad-A_{i}\left(x_{1}, \ldots, x_{i-1}, \lambda^{m} x_{i}, x_{i+1}, \ldots, x_{k}\right), y_{2}, \ldots, y_{n} \|\right] \\
& \leq \lim _{m \rightarrow \infty} \frac{1}{|\lambda|} \\
& \quad \times \sum_{j=0}^{\infty} \frac{1}{|\lambda|^{m+j}} \\
& \quad \times \varphi_{i}\left(x_{1}, \ldots, x_{i-1}, \lambda^{m+j} x_{i}, \lambda^{m+j} x_{i}, x_{i+1}, \ldots, x_{k}\right)
\end{aligned}
$$

$=0$,

and therefore $A_{i}=A_{i}^{\prime}$.

Theorem 11. Assume that for every $i \in\{1, \ldots, k\}, \varphi_{i}: V^{k+1} \rightarrow$ $[0, \infty)$ is a mapping such that

$$
\begin{aligned}
& \sum_{j=0}^{\infty}|\lambda|^{j}[ \varphi_{i}\left(\frac{x_{1}}{\lambda^{j}}, x_{2}, \ldots, x_{k+1}\right) \\
&+\cdots+\varphi_{i}\left(x_{1}, \ldots, x_{i-2}, \frac{x_{i-1}}{\lambda^{j}}, x_{i}, \ldots, x_{k+1}\right) \\
&+\varphi_{i}\left(x_{1}, \ldots, x_{i-1}, \frac{x_{i}}{\lambda^{j}}, \frac{x_{i+1}}{\lambda^{j}}, x_{i+2}, \ldots, x_{k+1}\right) \\
&+\varphi_{i}\left(x_{1}, \ldots, x_{i+1}, \frac{x_{i+2}}{\lambda^{j}}, x_{i+3}, \ldots, x_{k+1}\right) \\
&\left.+\cdots+\varphi_{i}\left(x_{1}, \ldots, x_{k}, \frac{x_{k+1}}{\lambda^{j}}\right)\right]<\infty, \\
&\left(x_{1}, \ldots, x_{k+1}\right) \in V^{k+1}
\end{aligned}
$$

If $f: V^{k} \rightarrow W$ is a function satisfying (36), then for every $i \epsilon$ $\{1, \ldots, k\}$, there exists a unique multi-Euler-Lagrange additive mapping $A_{i}: V^{k} \rightarrow W$ for which

$$
\begin{aligned}
& \left\|f\left(x_{1}, \ldots, x_{k}\right)-A_{i}\left(x_{1}, \ldots, x_{k}\right), y_{2}, \ldots, y_{n}\right\| \\
& \leq \frac{1}{2} \sum_{j=1}^{\infty}|\lambda|^{j-1} \\
& \quad \times \varphi_{i}\left(x_{1}, \ldots, x_{i-1}, \frac{x_{i}}{\lambda^{j}}, \frac{x_{i}}{\lambda^{j}}, x_{i+1}, \ldots, x_{k}\right), \\
& \quad\left(x_{1}, \ldots, x_{k}\right) \in V^{k}, \quad y_{2}, \ldots, y_{n} \in W .
\end{aligned}
$$

For every $i \in\{1, \ldots, k\}$, the function $A_{i}$ is given by

$$
\begin{array}{r}
A_{i}\left(x_{1}, \ldots, x_{k}\right) \\
:=\lim _{j \rightarrow \infty} \lambda^{j} f\left(x_{1}, \ldots, x_{i-1}, \frac{x_{i}}{\lambda^{j}}, x_{i+1}, \ldots, x_{k}\right), \\
\left(x_{1}, \ldots, x_{k}\right) \in V^{k} .
\end{array}
$$


Proof. Fix $x_{1}, \ldots, x_{k} \in V, y_{2}, \ldots, y_{n} \in W, j \in \mathbb{N} \cup\{0\}$ and $i \in$ $\{1, \ldots, k\}$. By (36) we get

$$
\begin{gathered}
\| f\left(x_{1}, \ldots, x_{k}\right)-\lambda f\left(x_{1}, \ldots, x_{i-1}, \frac{x_{i}}{\lambda}, x_{i+1}, \ldots, x_{k}\right), \\
y_{2}, \ldots, y_{n} \| \\
\leq \frac{1}{2} \varphi_{i}\left(x_{1}, \ldots, x_{i-1}, \frac{x_{i}}{\lambda}, \frac{x_{i}}{\lambda}, x_{i+1}, \ldots, x_{k}\right) .
\end{gathered}
$$

For any non-negative integers $l$ and $m$ with $0 \leq l<m$, using (49), we get

$$
\begin{aligned}
& \| \lambda^{l} f\left(x_{1}, \ldots, x_{i-1}, \frac{x_{i}}{\lambda^{l}}, x_{i+1}, \ldots, x_{k}\right) \\
& -\lambda^{m} f\left(x_{1}, \ldots, x_{i-1}, \frac{x_{i}}{\lambda^{m}}, x_{i+1}, \ldots, x_{k}\right), y_{2}, \ldots, y_{n} \| \\
& \leq \sum_{j=l}^{m-1} \frac{|\lambda|^{j}}{2} \\
& \quad \times \varphi_{i}\left(x_{1}, \ldots, x_{i-1}, \frac{x_{i}}{\lambda^{j+1}}, \frac{x_{i}}{\lambda^{j+1}}, x_{i+1}, \ldots, x_{k}\right),
\end{aligned}
$$

which tends to zero as $l$ tends to infinity. Therefore from (46), it follows that $\left\{\lambda^{j} f\left(x_{1}, \ldots, x_{i-1}, x_{i} / \lambda^{j}, x_{i+1}, \ldots, x_{k}\right)\right\}_{j \in \mathbb{N}}$ is a Cauchy sequence in $n$-Banach space $W$ and it thus converges. Hence, we can define $A_{i}: V^{k} \rightarrow W$ by

$$
A_{i}\left(x_{1}, \ldots, x_{k}\right):=\lim _{j \rightarrow \infty} \lambda^{j} f\left(x_{1}, \ldots, x_{i-1}, \frac{x_{i}}{\lambda^{j}}, x_{i+1}, \ldots, x_{k}\right) .
$$

Putting $l=0$, letting $m \rightarrow \infty$ in (50), and using (46), we see that (47) holds. The further part of the proof is similar to the proof of Theorem 10 .

As applications of Theorems 10 and 11, we get the following corollaries.

Corollary 12. Let $V$ be a real normed linear space and, $W$ be an $n$-Banach space. Assume also that $\theta \in[0, \infty)$ and $r \in(0, \infty)$ are such that $r \neq 1$. If $f: V^{k} \rightarrow W$ is a function satisfying

$$
\begin{aligned}
& \left\|\widetilde{D}_{i} f\left(x_{1}, \ldots, x_{k+1}\right), y_{2}, \ldots, y_{n}\right\| \\
& \leq \theta\left[\left\|x_{1}\right\|^{r} \cdots\left\|x_{i-1}\right\|^{r}\left(\left\|x_{i}\right\|^{r}+\left\|x_{i+1}\right\|^{r}\right)\right. \\
& \left.\times\left\|x_{i+2}\right\|^{r} \cdots\left\|x_{k+1}\right\|^{r}\right], \\
& \left(x_{1}, \ldots, x_{k+1}\right) \in V^{k+1}, \quad i \in\{1, \ldots, k\}, \\
& y_{2}, \ldots, y_{n} \in W,
\end{aligned}
$$

then for every $i \in\{1, \ldots, k\}$ there exists a unique multi-EulerLagrange additive mapping $A_{i}: V^{k} \rightarrow W$ for which

$$
\begin{aligned}
& \left\|f\left(x_{1}, \ldots, x_{k}\right)-A_{i}\left(x_{1}, \ldots, x_{k}\right), y_{2}, \ldots, y_{n}\right\| \\
& \leq \frac{\theta\left\|x_{1}\right\|^{r} \cdots\left\|x_{k}\right\|^{r}}{\left.|| \lambda|-| \lambda\right|^{r} \mid}
\end{aligned}
$$

for all $x_{1}, \ldots, x_{k} \in V, y_{2}, \ldots, y_{n} \in W$.

Corollary 13. Let $V$ be a real normed linear space and let $W$ be an $n$-Banach space. Assume also that $\theta \in[0, \infty)$ and $r, p, q \in$ $(0, \infty)$ are such that $r, p+q \in(0,1)$ or $r, p+q \in(1, \infty)$. If $f: V^{k} \rightarrow W$ is a function satisfying

$$
\begin{aligned}
& \left\|\widetilde{D}_{i} f\left(x_{1}, \ldots, x_{k+1}\right), y_{2}, \ldots, y_{n}\right\| \\
& \leq \theta\left\|x_{1}\right\|^{r} \cdots\left\|x_{i-1}\right\|^{r}\left(\left\|x_{i}\right\|^{p}\left\|x_{i+1}\right\|^{q}\right) \\
& \quad \times\left\|x_{i+2}\right\|^{r} \cdots\left\|x_{k+1}\right\|^{r}, \\
& \left(x_{1}, \ldots, x_{k+1}\right) \in V^{k+1}, \quad i \in\{1, \ldots, k\}, \quad y_{2}, \ldots, y_{n} \in W,
\end{aligned}
$$

then for every $i \in\{1, \ldots, k\}$, there exists a unique multi-EulerLagrange additive mapping $A_{i}: V^{k} \rightarrow W$ for which

$$
\begin{aligned}
& \left\|f\left(x_{1}, \ldots, x_{k}\right)-A_{i}\left(x_{1}, \ldots, x_{k}\right), y_{2}, \ldots, y_{n}\right\| \\
& \leq \frac{\theta\left\|x_{1}\right\|^{r} \cdots\left\|x_{i-1}\right\|^{r}\left\|x_{i}\right\|^{p+q}\left\|x_{i+1}\right\|^{r} \cdots\left\|x_{k}\right\|^{r}}{\left.2|| \lambda|-| \lambda\right|^{p+q} \mid},
\end{aligned}
$$

for all $x_{1}, \ldots, x_{k} \in V, y_{2}, \ldots, y_{n} \in W$.

From Corollary 13 we obtain the following corollary which corrects Theorems 2.1 and 2.2 from [20].

Corollary 14. Let $V$ be a real normed linear space and $W$ be an 2-Banach space. Assume also that $\theta \in[0, \infty)$ and $p, q \in(0, \infty)$ are such that $p+q \neq 1$. If $f: V \rightarrow W$ is a function satisfying

$$
\begin{aligned}
& \left\|f\left(x_{1}+x_{2}\right)-f\left(x_{1}\right)-f\left(x_{2}\right), y\right\| \\
& \quad \leq \theta\left\|x_{1}\right\|^{p}\left\|x_{2}\right\|^{q}, \quad x_{1}, x_{2} \in V, \quad y \in W,
\end{aligned}
$$

then there exists a unique additive mapping $A: V \rightarrow W$ for which

$$
\|f(x)-A(x), y\| \leq \frac{\theta\|x\|^{p+q}}{\left|2-2^{p+q}\right|}, \quad x \in V, y \in W .
$$

\section{Approximate Multi-Euler-Lagrange Quadratic Mappings}

In this section, we prove the stability of the system of equations defining multi-Euler-Lagrange quadratic mappings.

Throughout this section, let $V$ be a real linear space and let $W$ be an $n$-Banach space, and $a, b \in \mathbb{R} \backslash\{0\}$ are fixed with $\lambda:=a^{2}+b^{2} \neq 1$. 
Rassias [29] introduced the notion of a generalized Euler-Lagrange-type quadratic mapping, and investigated its generalized stability.

A mapping $f: V^{k} \rightarrow W$ is called a multi-Euler-Lagrange quadratic mapping, if it satisfies the Euler-Lagrange quadratic equations in each of their $k$ arguments:

$$
\begin{aligned}
f\left(x_{1}, \ldots, x_{i-1}, a x_{i}+b x_{i}^{\prime}, x_{i+1}, \ldots, x_{k}\right) \\
\quad+f\left(x_{1}, \ldots, x_{i-1}, b x_{i}-a x_{i}^{\prime}, x_{i+1}, \ldots, x_{k}\right) \\
=\left(a^{2}+b^{2}\right) \\
\quad \times\left[f\left(x_{1}, \ldots, x_{k}\right)+f\left(x_{1}, \ldots, x_{i-1}, x_{i}^{\prime}, x_{i+1}, \ldots, x_{k}\right)\right],
\end{aligned}
$$

for all $i \in\{1, \ldots, k\}$ and all $x_{1}, \ldots, x_{i-1}, x_{i}, x_{i}^{\prime}, x_{i+1}, \ldots, x_{k} \in V$.

If $a=b=1$, then the multi-Euler-Lagrange quadratic mapping is multiquadratic (see [30]). Letting $x_{i}=x_{i}^{\prime}=0$ in (58), we get $f\left(x_{1}, \ldots, x_{i-1}, 0, x_{i+1}, \ldots, x_{k}\right)=0$. Putting $x_{i}^{\prime}=0$ in (58), we have

$$
\begin{aligned}
f( & \left.x_{1}, \ldots, x_{i-1}, a x_{i}, x_{i+1}, \ldots, x_{k}\right) \\
& \quad+f\left(x_{1}, \ldots, x_{i-1}, b x_{i}, x_{i+1}, \ldots, x_{k}\right) \\
= & \lambda f\left(x_{1}, \ldots, x_{k}\right) .
\end{aligned}
$$

Replacing $x_{i}$ by $a x_{i}$ and $x_{i}^{\prime}$ by $b x_{i}$ in (58), respectively, we obtain

$$
\begin{aligned}
& f\left(x_{1}, \ldots, x_{i-1}, \lambda x_{i}, x_{i+1}, \ldots, x_{k}\right) \\
&=\lambda[ f\left(x_{1}, \ldots, x_{i-1}, a x_{i}, x_{i+1}, \ldots, x_{k}\right) \\
&\left.+f\left(x_{1}, \ldots, x_{i-1}, b x_{i}, x_{i+1}, \ldots, x_{k}\right)\right] .
\end{aligned}
$$

From (59) and (60), one gets

$$
f\left(x_{1}, \ldots, x_{i-1}, \lambda x_{i}, x_{i+1}, \ldots, x_{k}\right)=\lambda^{2} f\left(x_{1}, \ldots, x_{k}\right),
$$

for all $i \in\{1, \ldots, k\}$ and all $x_{1}, \ldots, x_{k} \in V$.

For a given mapping $f: V^{k} \rightarrow W$, we define the difference operators

$$
\begin{array}{rl}
\widehat{D}_{i} & f\left(x_{1}, \ldots, x_{k+1}\right) \\
:= & f\left(x_{1}, \ldots, x_{i-1}, a x_{i}+b x_{i+1}, x_{i+2}, \ldots, x_{k+1}\right) \\
& +f\left(x_{1}, \ldots, x_{i-1}, b x_{i}-a x_{i+1}, x_{i+2}, \ldots, x_{k+1}\right)-\left(a^{2}+b^{2}\right) \\
& \times\left[f\left(x_{1}, \ldots, x_{i}, x_{i+2}, \ldots, x_{k+1}\right)\right. \\
& \left.\quad+f\left(x_{1}, \ldots, x_{i-1}, x_{i+1}, \ldots, x_{k}\right)\right], \\
\left(x_{1}, \ldots, x_{k+1}\right) \in V^{k+1}, \quad i \in\{1, \ldots, k\} .
\end{array}
$$

Theorem 15. Assume that for everyi $\in\{1, \ldots, k\}, \varphi_{i}: V^{k+1} \rightarrow$ $[0, \infty)$ is a mapping such that

$$
\begin{aligned}
\sum_{j=0}^{\infty} \frac{1}{\lambda^{2 j}} & \\
\times & {\left[\varphi_{i}\left(\lambda^{j} x_{1}, x_{2}, \ldots, x_{k+1}\right)\right.} \\
& +\cdots+\varphi_{i}\left(x_{1}, \ldots, x_{i-2}, \lambda^{j} x_{i-1}, x_{i}, \ldots, x_{k+1}\right) \\
& +\varphi_{i}\left(x_{1}, \ldots, x_{i-1}, \lambda^{j} x_{i}, \lambda^{j} x_{i+1}, x_{i+2}, \ldots, x_{k+1}\right) \\
& +\varphi_{i}\left(x_{1}, \ldots, x_{i+1}, \lambda^{j} x_{i+2}, x_{i+3}, \ldots, x_{k+1}\right) \\
& \left.+\cdots+\varphi_{i}\left(x_{1}, \ldots, x_{k}, \lambda^{j} x_{k+1}\right)\right]<\infty,
\end{aligned}
$$

$$
\left(x_{1}, \ldots, x_{k+1}\right) \in V^{k+1} \text {. }
$$

If $f: V^{k} \rightarrow W$ is a function satisfying condition (11) and

$$
\begin{aligned}
& \left\|\widehat{D}_{i} f\left(x_{1}, \ldots, x_{k+1}\right), y_{2}, \ldots, y_{n}\right\| \\
& \leq \varphi_{i}\left(x_{1}, \ldots, x_{k+1}\right), \\
& \left(x_{1}, \ldots, x_{k+1}\right) \in V^{k+1}, \quad i \in\{1, \ldots, k\}, \\
& y_{2}, \ldots, y_{n} \in W,
\end{aligned}
$$

then for every $i \in\{1, \ldots, k\}$, there exists a unique multi-EulerLagrange quadratic mapping $Q_{i}: V^{k} \rightarrow W$ for which

$$
\begin{aligned}
& \left\|f\left(x_{1}, \ldots, x_{k}\right)-Q_{i}\left(x_{1}, \ldots, x_{k}\right), y_{2}, \ldots, y_{n}\right\| \\
& \leq \sum_{j=0}^{\infty}\left[\frac{1}{\lambda^{2 j+1}} \varphi_{i}\left(x_{1}, \ldots, x_{i-1}, \lambda^{j} x_{i}, 0, x_{i+1}, \ldots, x_{k}\right)\right. \\
& \quad+\frac{1}{\lambda^{2 j+2}} \varphi_{i}\left(x_{1}, \ldots, x_{i-1}, a \lambda^{j} x_{i},\right.
\end{aligned}
$$

$$
\left.\left.b \lambda^{j} x_{i}, x_{i+1}, \ldots, x_{k}\right)\right],
$$

$$
\left(x_{1}, \ldots, x_{k}\right) \in V^{k}, \quad y_{2}, \ldots, y_{n} \in W \text {. }
$$

For every $i \in\{1, \ldots, k\}$, the function $Q_{i}$ is given by

$$
\begin{aligned}
& Q_{i}\left(x_{1}, \ldots, x_{k}\right) \\
& :=\lim _{j \rightarrow \infty} \frac{1}{\lambda^{2 j}} \\
& \times f\left(x_{1}, \ldots, x_{i-1}, \lambda^{j} x_{i}, x_{i+1}, \ldots, x_{k}\right), \\
& \left(x_{1}, \ldots, x_{k}\right) \in V^{k} \text {. }
\end{aligned}
$$


Proof. Fix $x_{1}, \ldots, x_{k} \in V, y_{2}, \ldots, y_{n} \in W, j \in \mathbb{N} \cup\{0\}$ and $i \in$ $\{1, \ldots, k\}$. By $(64)$, we get

$$
\begin{aligned}
& \| f\left(x_{1}, \ldots, x_{i-1}, a x_{i}, x_{i+1}, \ldots, x_{k}\right) \\
& +f\left(x_{1}, \ldots, x_{i-1}, b x_{i}, x_{i+1}, \ldots, x_{k}\right) \\
& -\lambda f\left(x_{1}, \ldots, x_{k}\right), y_{2}, \ldots, y_{n} \| \\
& \quad \leq \varphi_{i}\left(x_{1}, \ldots, x_{i}, 0, x_{i+1}, \ldots, x_{k}\right), \\
& \| f\left(x_{1}, \ldots, x_{i-1}, \lambda x_{i}, x_{i+1}, \ldots, x_{k}\right) \\
& -\lambda f\left(x_{1}, \ldots, x_{i-1}, a x_{i}, x_{i+1}, \ldots, x_{k}\right) \\
& -\lambda f\left(x_{1}, \ldots, x_{i-1}, b x_{i}, x_{i+1}, \ldots, x_{k}\right), \\
& y_{2}, \ldots, y_{n} \| \\
& \quad \leq \varphi_{i}\left(x_{1}, \ldots, x_{i-1}, a x_{i}, b x_{i}, x_{i+1}, \ldots, x_{k}\right) .
\end{aligned}
$$

From (67), we obtain

$$
\begin{aligned}
\| \frac{1}{\lambda^{2}} f & \left(x_{1}, \ldots, x_{i-1}, \lambda x_{i}, x_{i+1}, \ldots, x_{k}\right) \\
- & f\left(x_{1}, \ldots, x_{k}\right), y_{2}, \ldots, y_{n} \| \\
\leq & \frac{1}{\lambda} \varphi_{i}\left(x_{1}, \ldots, x_{i}, 0, x_{i+1}, \ldots, x_{k}\right)+\frac{1}{\lambda^{2}} \\
\quad & \times \varphi_{i}\left(x_{1}, \ldots, x_{i-1}, a x_{i}, b x_{i}, x_{i+1}, \ldots, x_{k}\right),
\end{aligned}
$$

and consequently for any non-negative integers $l$ and $m$ such that $l<m$, we get

$$
\begin{aligned}
& \| \frac{1}{\lambda^{2 l}} f\left(x_{1}, \ldots, x_{i-1}, \lambda^{l} x_{i}, x_{i+1}, \ldots, x_{k}\right)-\frac{1}{\lambda^{2 m}} \\
& \quad \times f\left(x_{1}, \ldots, x_{i-1}, \lambda^{m} x_{i}, x_{i+1}, \ldots, x_{k}\right), y_{2}, \ldots, y_{n} \| \\
& \leq \sum_{j=l}^{m-1} \| \frac{1}{\lambda^{2(j+1)}} f\left(x_{1}, \ldots, x_{i-1}, \lambda^{j+1} x_{i}, x_{i+1}, \ldots, x_{k}\right) \\
& \quad-\frac{1}{\lambda^{2 j}} f\left(x_{1}, \ldots, x_{i-1}, \lambda^{j} x_{i}, x_{i+1}, \ldots, x_{k}\right), \\
& \quad y_{2}, \ldots, y_{n} \| \\
& \leq \sum_{j=l}^{m-1}\left[\frac{1}{\lambda^{2 j+1}} \varphi_{i}\left(x_{1}, \ldots, x_{i-1}, \lambda^{j} x_{i}, 0, x_{i+1}, \ldots, x_{k}\right)\right. \\
& \quad+\frac{1}{\lambda^{2 j+2}} \\
& \left.\quad \times \varphi_{i}\left(x_{1}, \ldots, x_{i-1}, a \lambda^{j} x_{i}, b \lambda^{j} x_{i}, x_{i+1}, \ldots, x_{k}\right)\right] .
\end{aligned}
$$

Therefore from (63), it follows that $\left\{\left(1 / \lambda^{2 j}\right) f\left(x_{1}, \ldots, x_{i-1}\right.\right.$, $\left.\left.\lambda^{j} x_{i}, x_{i+1}, \ldots, x_{k}\right)\right\}_{j \in \mathbb{N}}$ is a Cauchy sequence. Since $W$ is an $n$ Banach space, this sequence is convergent and we define
$Q_{i}: V^{k} \rightarrow W$ by (66). Putting $l=0$, letting $m \rightarrow \infty$ in (69) and using Lemma 4 and (63), we see that (65) holds.

Now, fix also $x_{i}^{\prime} \in V$ and note that according to (64), we have

$$
\begin{aligned}
& \| \frac{1}{\lambda^{2 j}} \widehat{D}_{i} f\left(x_{1}, \ldots, x_{i-1}, \lambda^{j} x_{i}, \lambda^{j} x_{i}^{\prime}, x_{i+1}, \ldots, x_{k}\right), \\
& y_{2}, \ldots, y_{n} \| \\
& \quad \leq \frac{1}{\lambda^{2 j}} \varphi_{i}\left(x_{1}, \ldots, x_{i-1}, \lambda^{j} x_{i}, \lambda^{j} x_{i}^{\prime}, x_{i+1}, \ldots, x_{k}\right) .
\end{aligned}
$$

Next, fix $s \in\{1, \ldots, k\} \backslash\{i\}, x_{s}^{\prime} \in V$, and assume that $s<i$ (the same arguments apply to the case where $s>i$ ). From (64), it follows that

$$
\begin{gathered}
\| \frac{1}{\lambda^{2 j}} \widehat{D}_{s} f\left(x_{1}, \ldots, x_{s}, x_{s}^{\prime}, x_{s+1}, \ldots, x_{i-1},\right. \\
\left.\lambda^{j} x_{i}, x_{i+1}, \ldots, x_{k}\right), y_{2}, \ldots, y_{n} \| \\
\leq \frac{1}{\lambda^{2 j}} \varphi_{s}\left(x_{1}, \ldots, x_{s}, x_{s}^{\prime}, x_{s+1}, \ldots, x_{i-1},\right. \\
\left.\lambda^{j} x_{i}, x_{i+1}, \ldots, x_{k}\right) .
\end{gathered}
$$

Letting $j \rightarrow \infty$ in the above two inequalities and using (63), and Lemma 4 we see that the mapping $Q_{i}$ is multi-EulerLagrange quadratic.

Now, let us finally assume that $Q_{i}^{\prime}: V^{k} \rightarrow W$ is another multi-Euler-Lagrange quadratic mapping satisfying (65) and note that according to (61) and using Lemma 4 , and (63) we have

$$
\begin{aligned}
& \left\|Q_{i}\left(x_{1}, \ldots, x_{k}\right)-Q_{i}^{\prime}\left(x_{1}, \ldots, x_{k}\right), y_{2}, \ldots, y_{n}\right\| \\
& =\lim _{m \rightarrow \infty} \frac{1}{\lambda^{2 m}} \| Q_{i}\left(x_{1}, \ldots, x_{i-1}, \lambda^{m} x_{i}, x_{i+1}, \ldots, x_{k}\right) \\
& -Q_{i}^{\prime}\left(x_{1}, \ldots, x_{i-1}, \lambda^{m} x_{i}, x_{i+1}, \ldots, x_{k}\right), \\
& y_{2}, \ldots, y_{n} \| \\
& \leq \lim _{m \rightarrow \infty} \frac{1}{\lambda^{2 m}}\left[\| Q_{i}\left(x_{1}, \ldots, x_{i-1}, \lambda^{m} x_{i}, x_{i+1}, \ldots, x_{k}\right)\right. \\
& -f\left(x_{1}, \ldots, x_{i-1}, \lambda^{m} x_{i}, x_{i+1}, \ldots, x_{k}\right), \\
& y_{2}, \ldots, y_{n} \| \\
& +\| f\left(x_{1}, \ldots, x_{i-1}, \lambda^{m} x_{i}, x_{i+1}, \ldots, x_{k}\right) \\
& -Q_{i}\left(x_{1}, \ldots, x_{i-1}, \lambda^{m} x_{i}, x_{i+1}, \ldots, x_{k}\right), \\
& \left.y_{2}, \ldots, y_{n} \|\right]
\end{aligned}
$$




$$
\begin{aligned}
\leq \lim _{m \rightarrow \infty} \sum_{j=0}^{\infty} & {\left[\frac{1}{\lambda^{2(m+j)+1}}\right.} \\
& \times \varphi_{i}\left(x_{1}, \ldots, x_{i-1}, \lambda^{m+j} x_{i}, 0, x_{i+1}, \ldots, x_{k}\right) \\
& +\frac{1}{\lambda^{2(m+j)+2}} \\
& \times \varphi_{i}\left(x_{1}, \ldots, x_{i-1}, a \lambda^{m+j} x_{i},\right. \\
& \left.\left.b \lambda^{m+j} x_{i}, x_{i+1}, \ldots, x_{k}\right)\right]
\end{aligned}
$$

$=0$.

Therefore, by Lemma 4 , we can conclude that $Q_{i}=Q_{i}^{\prime}$.

Similar to Theorem 15, one can get the following.

Theorem 16. Assume that for every $i \in\{1, \ldots, k\}, \varphi_{i}$ : $V^{k+1} \rightarrow[0, \infty)$ is a mapping such that

$$
\begin{aligned}
\sum_{j=0}^{\infty} \lambda^{2 j}[ & \varphi_{i}\left(\frac{x_{1}}{\lambda^{j}}, x_{2}, \ldots, x_{k+1}\right) \\
& +\cdots+\varphi_{i}\left(x_{1}, \ldots, x_{i-2}, \frac{x_{i-1}}{\lambda^{j}}, x_{i}, \ldots, x_{k+1}\right) \\
& +\varphi_{i}\left(x_{1}, \ldots, x_{i-1}, \frac{x_{i}}{\lambda^{j}}, \frac{x_{i+1}}{\lambda^{j}}, x_{i+2}, \ldots, x_{k+1}\right) \\
& +\varphi_{i}\left(x_{1}, \ldots, x_{i+1}, \frac{x_{i+2}}{\lambda^{j}}, x_{i+3}, \ldots, x_{k+1}\right) \\
& \left.+\cdots+\varphi_{i}\left(x_{1}, \ldots, x_{k}, \frac{x_{k+1}}{\lambda^{j}}\right)\right]<\infty, \\
& \left(x_{1}, \ldots, x_{k+1}\right) \in V^{k+1} .
\end{aligned}
$$

If $f: V^{k} \rightarrow W$ is a function satisfying condition (11) and

$$
\begin{array}{r}
\left\|\widehat{D}_{i} f\left(x_{1}, \ldots, x_{k+1}\right), y_{2}, \ldots, y_{n}\right\| \leq \varphi_{i}\left(x_{1}, \ldots, x_{k+1}\right), \\
\left(x_{1}, \ldots, x_{k+1}\right) \in V^{k+1}, \quad i \in\{1, \ldots, k\}, \\
y_{2}, \ldots, y_{n} \in W,
\end{array}
$$

then for every $i \in\{1, \ldots, k\}$, there exists a unique multi-EulerLagrange quadratic mapping $Q_{i}: V^{k} \rightarrow W$ for which

$$
\begin{aligned}
& \left\|f\left(x_{1}, \ldots, x_{k}\right)-Q_{i}\left(x_{1}, \ldots, x_{k}\right), y_{2}, \ldots, y_{n}\right\| \\
& \leq \sum_{j=0}^{\infty}\left[\lambda^{2 j+1}\right. \\
& \quad \times \varphi_{i}\left(x_{1}, \ldots, x_{i-1}, \frac{x_{i}}{\lambda^{j+1}}, 0, x_{i+1}, \ldots, x_{k}\right) \\
& \left.\quad+\lambda^{2 j} \varphi_{i}\left(x_{1}, \ldots, x_{i-1}, \frac{a x_{i}}{\lambda^{j+1}}, \frac{b x_{i}}{\lambda^{j+1}}, x_{i+1}, \ldots, x_{k}\right)\right], \\
& \quad\left(x_{1}, \ldots, x_{k}\right) \in V^{k}, \quad y_{2}, \ldots, y_{n} \in W .
\end{aligned}
$$

For every $i \in\{1, \ldots, k\}$ the function $Q_{i}$ is given by

$$
\begin{array}{r}
Q_{i}\left(x_{1}, \ldots, x_{k}\right) \\
\quad:=\lim _{j \rightarrow \infty} \lambda^{2 j} f\left(x_{1}, \ldots, x_{i-1}, \frac{x_{i}}{\lambda^{j}}, x_{i+1}, \ldots, x_{k}\right), \\
\left(x_{1}, \ldots, x_{k}\right) \in V^{k} .
\end{array}
$$

Proof. Fix $x_{1}, \ldots, x_{k} \in V, y_{2}, \ldots, y_{n} \in W, j \in \mathbb{N} \cup\{0\}$ and $i \in\{1, \ldots, k\}$. By $(74)$, we obtain

$$
\begin{aligned}
\| \lambda^{2} f\left(x_{1}, \ldots, x_{i-1}, \frac{x_{i}}{\lambda}, x_{i+1}, \ldots, x_{k}\right) \\
-f\left(x_{1}, \ldots, x_{k}\right), y_{2}, \ldots, y_{n} \| \\
\leq \lambda \varphi_{i}\left(x_{1}, \ldots, x_{i-1}, \frac{x_{i}}{\lambda}, 0, x_{i+1}, \ldots, x_{k}\right), \\
\quad+\varphi_{i}\left(x_{1}, \ldots, x_{i-1}, \frac{a x_{i}}{\lambda}, \frac{b x_{i}}{\lambda}, x_{i+1}, \ldots, x_{k}\right),
\end{aligned}
$$

and consequently for any non-negative integers $l$ and $m$ such that $l<m$, we get

$$
\begin{aligned}
& \| \lambda^{2 l} f\left(x_{1}, \ldots, x_{i-1}, \frac{x_{i}}{\lambda^{l}}, x_{i+1}, \ldots, x_{k}\right) \\
& -\lambda^{2 m} f\left(x_{1}, \ldots, x_{i-1}, \frac{x_{i}}{\lambda^{m}}, x_{i+1}, \ldots, x_{k}\right), y_{2}, \ldots, y_{n} \| \\
& \leq \sum_{j=l}^{m-1} \| \lambda^{2(j+1)} f\left(x_{1}, \ldots, x_{i-1}, \frac{x_{i}}{\lambda^{j+1}}, x_{i+1}, \ldots, x_{k}\right) \\
& \quad-\lambda^{2 j} f\left(x_{1}, \ldots, x_{i-1}, \frac{x_{i}}{\lambda^{j}}, x_{i+1}, \ldots, x_{k}\right), y_{2}, \ldots, y_{n} \| \\
& \leq \sum_{j=l}^{m-1}\left[\lambda^{2 j+1} \varphi_{i}\left(x_{1}, \ldots, x_{i-1}, \frac{x_{i}}{\lambda^{j+1}}, 0, x_{i+1}, \ldots, x_{k}\right)\right. \\
& \left.\quad+\lambda^{2 j} \varphi_{i}\left(x_{1}, \ldots, x_{i-1}, \frac{a x_{i}}{\lambda^{j+1}}, \frac{b x_{i}}{\lambda^{j+1}}, x_{i+1}, \ldots, x_{k}\right)\right]
\end{aligned}
$$

Therefore, from (73), it follows that $\left\{\lambda^{2 j} f\left(x_{1}, \ldots, x_{i-1}, x_{i} / \lambda^{j}\right.\right.$, $\left.\left.x_{i+1}, \ldots, x_{k}\right)\right\}_{j \in \mathbb{N}}$ is a Cauchy sequence. Since $W$ is an $n$ Banach space, this sequence is convergent and we define $Q_{i}$ : $V^{k} \rightarrow W$ by (76). Putting $l=0$, letting $m \rightarrow \infty$ in (78), and using Lemma 4 and (73) we see that (75) holds. The further part of the proof is similar to the proof of Theorem 15.

As applications of Theorems 15 and 16, we get the following corollaries.

Corollary 17. Let $V$ be a real normed linear space and, $W$ be an $n$-Banach space. Assume also that $\theta \in[0, \infty)$ and $r \epsilon$ $(0, \infty)$ are such that $r \neq 1$. If $f: V^{k} \rightarrow W$ is a function satisfying

$$
\begin{aligned}
& \left\|\widehat{D}_{i} f\left(x_{1}, \ldots, x_{k+1}\right), y_{2}, \ldots, y_{n}\right\| \\
& \leq \theta\left[\left\|x_{1}\right\|^{r} \cdots\left\|x_{i-1}\right\|^{r}\left(\left\|x_{i}\right\|^{r}+\left\|x_{i+1}\right\|^{r}\right)\right. \\
& \left.\quad \times\left\|x_{i+2}\right\|^{r} \cdots\left\|x_{k+1}\right\|^{r}\right],
\end{aligned}
$$




$$
\begin{array}{r}
\left(x_{1}, \ldots, x_{k+1}\right) \in V^{k+1}, \quad i \in\{1, \ldots, k\}, \\
y_{2}, \ldots, y_{n} \in W,
\end{array}
$$

then for every $i \in\{1, \ldots, k\}$, there exists a unique multi-EulerLagrange quadratic mapping $Q_{i}: V^{k} \rightarrow W$ for which

$$
\begin{gathered}
\left\|f\left(x_{1}, \ldots, x_{k}\right)-Q_{i}\left(x_{1}, \ldots, x_{k}\right), y_{2}, \ldots, y_{n}\right\| \\
\leq \frac{\theta\left\|x_{1}\right\|^{r} \cdots\left\|x_{k}\right\|^{r}\left(\lambda+|a|^{r}+|b|^{r}\right)}{\left|\lambda^{2}-\lambda^{r}\right|},
\end{gathered}
$$

for all $x_{1}, \ldots, x_{k} \in V, y_{2}, \ldots, y_{n} \in W$.

Corollary 18. Let $V$ be a real normed linear space and let $W$ be an $n$-Banach space. Assume also that $\theta \in[0, \infty)$ and $r, p, q \in$ $(0, \infty)$ are such that $r, p+q \in(0,2)$ or $r, p+q \in(2, \infty)$. If $f: V^{k} \rightarrow W$ is a function satisfying

$$
\begin{aligned}
& \left\|\widehat{D}_{i} f\left(x_{1}, \ldots, x_{k+1}\right), y_{2}, \ldots, y_{n}\right\| \\
& \leq \theta\left\|x_{1}\right\|^{r} \cdots\left\|x_{i-1}\right\|^{r}\left(\left\|x_{i}\right\|^{p}\left\|x_{i+1}\right\|^{q}\right) \\
& \times\left\|x_{i+2}\right\|^{r} \cdots\left\|x_{k+1}\right\|^{r}, \\
& \left(x_{1}, \ldots, x_{k+1}\right) \in V^{k+1}, \quad i \in\{1, \ldots, k\}, \\
& y_{2}, \ldots, y_{n} \in W,
\end{aligned}
$$

then for every $i \in\{1, \ldots, k\}$, there exists a unique multi-EulerLagrange quadratic mapping $Q_{i}: V^{k} \rightarrow W$ for which

$$
\begin{aligned}
& \left\|f\left(x_{1}, \ldots, x_{k}\right)-Q_{i}\left(x_{1}, \ldots, x_{k}\right), y_{2}, \ldots, y_{n}\right\| \\
& \leq \frac{|a|^{p}|b|^{q} \theta\left\|x_{1}\right\|^{r} \cdots\left\|x_{i-1}\right\|^{r}\left\|x_{i}\right\|^{p+q}\left\|x_{i+1}\right\|^{r} \cdots\left\|x_{k}\right\|^{r}}{\left|\lambda^{2}-\lambda^{p+q}\right|},
\end{aligned}
$$

for all $x_{1}, \ldots, x_{k} \in V, y_{2}, \ldots, y_{n} \in W$.

For $a=b=1$, Corollary 18 yields the following corollary which corrects Theorems 4.1 and 4.2 from [20].

Corollary 19. Let $V$ be a real normed linear space and let $W$ be an 2-Banach space. Assume also that $\theta \in[0, \infty)$ and $p, q \in$ $(0, \infty)$ are such that $p+q \neq 2$. If $f: V \rightarrow W$ is a function satisfying

$$
\begin{aligned}
& \left\|f\left(x_{1}+x_{2}\right)-f\left(x_{1}\right)-f\left(x_{2}\right), y\right\| \\
& \leq \theta\left\|x_{1}\right\|^{p}\left\|x_{2}\right\|^{q}, \quad x_{1}, x_{2} \in V, \quad y \in W,
\end{aligned}
$$

then there exists a unique quadratic mapping $Q: V \rightarrow W$ for which

$$
\|f(x)-Q(x), y\| \leq \frac{\theta\|x\|^{p+q}}{\left|4-2^{p+q}\right|}, \quad x \in V, \quad y \in W .
$$

\section{Acknowledgments}

This project was supported by the National Natural Science Foundation of China (NNSFC) (Grant no. 11171022). The author would like to thank Professor Krzysztof Ciepliński and anonymous referees for their valuable comments and suggestions.

\section{References}

[1] W. Prager and J. Schwaiger, "Multi-affine and multi-Jensen functions and their connection with generalized polynomials," Aequationes Mathematicae, vol. 69, no. 1-2, pp. 41-57, 2005.

[2] J. Schwaiger and W. Prager, "Jensen, multi-Jensen and polynomial functions on arbitrary abelian groups," Aequationes Mathematicae, vol. 80, no. 1-2, pp. 209-221, 2010.

[3] W. Prager and J. Schwaiger, "Stability of the multi-Jensen equation," Bulletin of the Korean Mathematical Society, vol. 45, no. 1, pp. 133-142, 2008.

[4] K. Ciepliński, "On multi-Jensen functions and Jensen difference," Bulletin of the Korean Mathematical Society, vol. 45, no. 4, pp. 729-737, 2008.

[5] K. Ciepliński, "Stability of the multi-Jensen equation," Journal of Mathematical Analysis and Applications, vol. 363, no. 1, pp. 249-254, 2010.

[6] D. G. Bourgin, "Classes of transformations and bordering transformations," Bulletin of the American Mathematical Society, vol. 57, pp. 223-237, 1951.

[7] P. Găvruța, "A generalization of the Hyers-Ulam-Rassias stability of approximately additive mappings," Journal of Mathematical Analysis and Applications, vol. 184, no. 3, pp. 431-436, 1994.

[8] T. Aoki, "On the stability of the linear transformation in Banach spaces," Journal of the Mathematical Society of Japan, vol. 2, pp. 64-66, 1950.

[9] T. M. Rassias, "On the stability of the linear mapping in Banach spaces," Proceedings of the American Mathematical Society, vol. 72, no. 2, pp. 297-300, 1978.

[10] J. Brzdęk and K. Ciepliński, "Remarks on the Hyers-Ulam stability of some systems of functional equations," Applied Mathematics and Computation, vol. 219, no. 8, pp. 4096-4105, 2012.

[11] K. Ciepliński, "Stability of multi-Jensen mappings in nonArchimedean normed spaces," in Functional Equations in Mathematical Analysis, pp. 79-86, Springer, New York, NY, USA, 2012.

[12] K. Ciepliński and T. Z. Xu, "Approximate multi-Jensen and multi-quadratic mappings in 2-Banach spaces," Carpathian Journal of Mathematics, vol. 29, pp. 159-166, 2013.

[13] T. Z. Xu, "On the stability of multi-Jensen mappings in $\beta$ normed spaces," Applied Mathematics Letters, vol. 25, no. 11, pp. 1866-1870, 2012

[14] T. Z. Xu, "Stability of multi-Jensen mappings in non-Archimedean normed spaces," Journal of Mathematical Physics, vol. 53, no. 2, Article ID 023507, 9 pages, 2012.

[15] R. P. Agarwal, B. Xu, and W. Zhang, "Stability of functional equations in single variable," Journal of Mathematical Analysis and Applications, vol. 288, no. 2, pp. 852-869, 2003.

[16] N. Brillouët-Belluot, J. Brzdęk, and K. Ciepliński, "On some recent developments in Ulam's type stability," Abstract and Applied Analysis, vol. 2012, Article ID 716936, 41 pages, 2012.

[17] S. M. Jung, Hyers-Ulam-Rassias Stability of Functional Equations in Nonlinear Analysis, vol. 48 of Springer Optimization and Its Applications, Springer, New York, NY, USA, 2011.

[18] S. M. Ulam, A Collection of Mathematical Problems, Interscience Tracts in Pure and Applied Mathematics, Interscience Publishers, New York, NY, USA, 1960.

[19] T. Z. Xu and J. M. Rassias, "On the Hyers-Ulam stability of a general mixed additive and cubic functional equation in $n$ Banach spaces," Abstract and Applied Analysis, vol. 2012, Article ID 926390, 23 pages, 2012. 
[20] W. G. Park, "Approximate additive mappings in 2-Banach spaces and related topics," Journal of Mathematical Analysis and Applications, vol. 376, no. 1, pp. 193-202, 2011.

[21] S. Gähler, "2-metrische Räume und ihre topologische Struktur," Mathematische Nachrichten, vol. 26, no. 1-4, pp. 115-148, 1963.

[22] S. Gähler, "Lineare 2-normierte Räume," Mathematische Nachrichten, vol. 28, pp. 1-43, 1964.

[23] Y. J. Cho, P. C. S. Lin, S. S. Kim, and A. Misiak, Theory of 2-Inner Product Spaces, Nova Science, New York, NY, USA, 2001.

[24] A. Misiak, " $n$-inner product spaces," Mathematische Nachrichten, vol. 140, pp. 299-319, 1989.

[25] X. Y. Chen and M. M. Song, "Characterizations on isometries in linear n-normed spaces," Nonlinear Analysis: Theory, Methods \& Applications, vol. 72, no. 3-4, pp. 1895-1901, 2010.

[26] S. Gähler, "Über 2-Banach-Räume," Mathematische Nachrichten, vol. 42, no. 4-6, pp. 335-347, 1969.

[27] A. G. White Jr., "2-Banach spaces," Mathematische Nachrichten, vol. 42, no. 1-3, pp. 43-60, 1969.

[28] K. Ciepliński, "Generalized stability of multi-additive mappings," Applied Mathematics Letters, vol. 23, no. 10, pp. 12911294, 2010.

[29] J. M. Rassias, "On the stability of the general Euler-Lagrange functional equation," Demonstratio Mathematica, vol. 29, no. 4, pp. 755-766, 1996.

[30] K. Ciepliński, "On the generalized Hyers-Ulam stability of multi-quadratic mappings," Computers \& Mathematics with Applications, vol. 62, no. 9, pp. 3418-3426, 2011. 


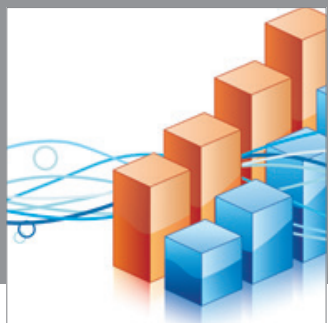

Advances in

Operations Research

mansans

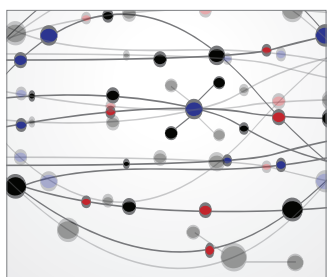

The Scientific World Journal
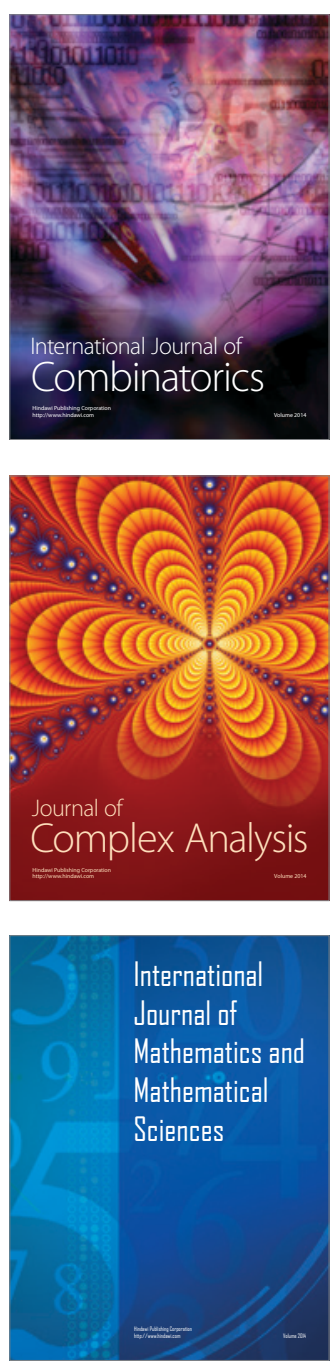
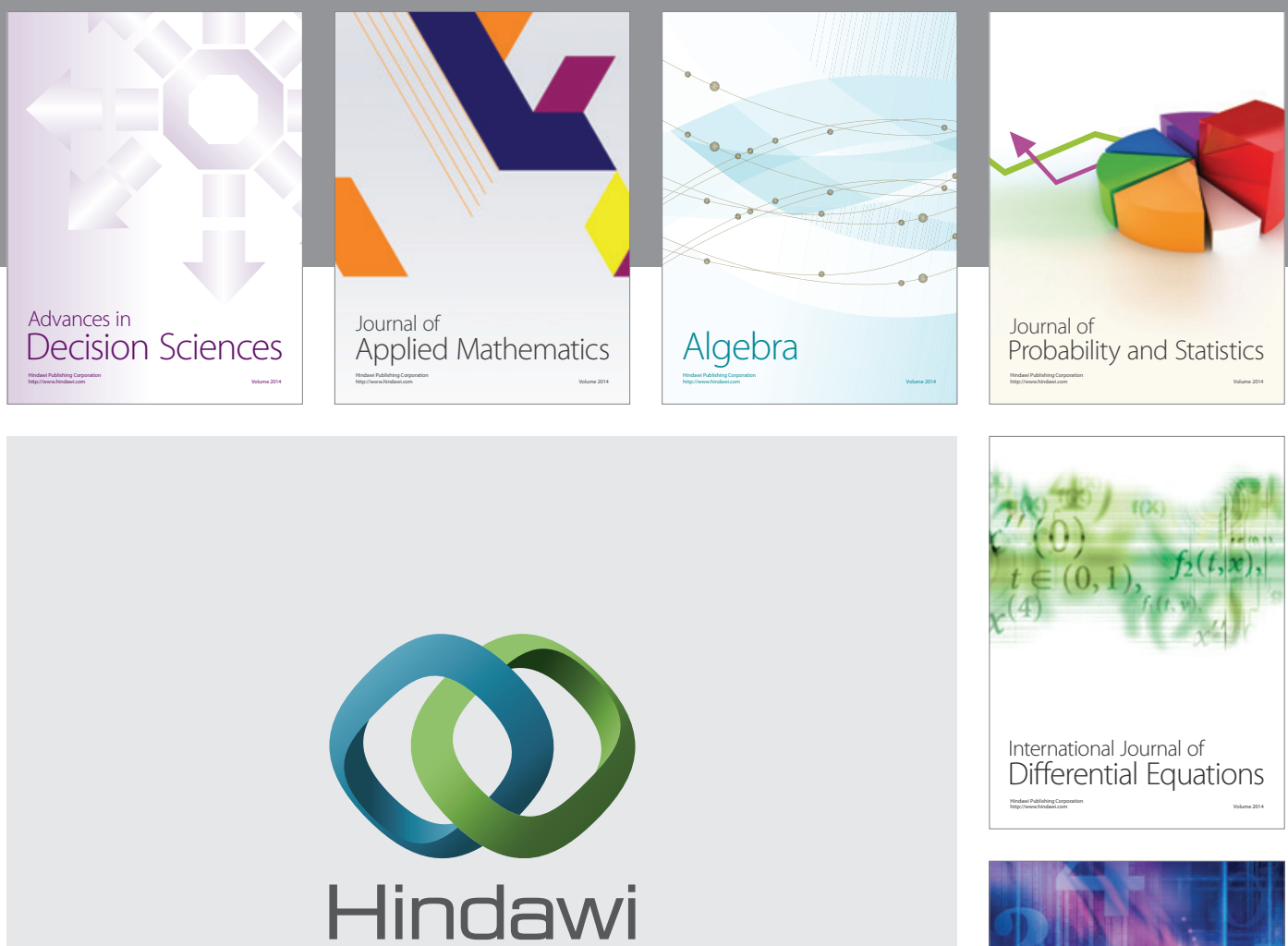

Submit your manuscripts at http://www.hindawi.com
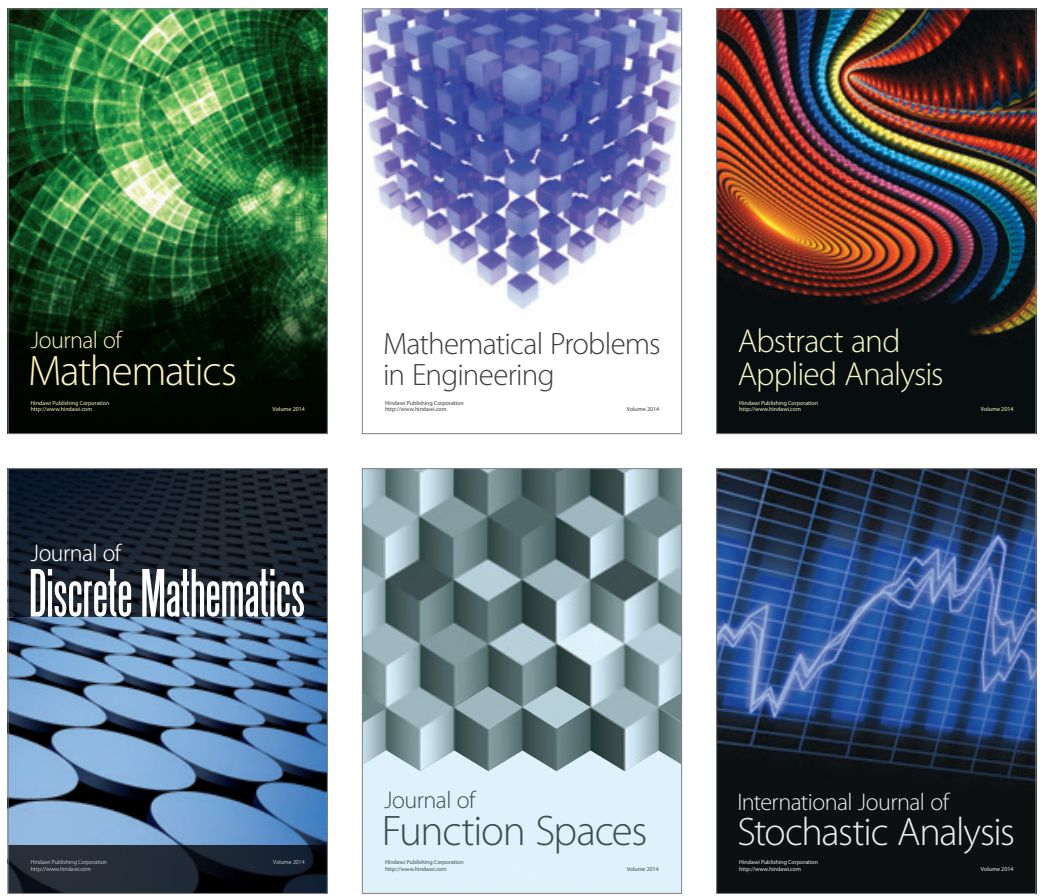

Journal of

Function Spaces

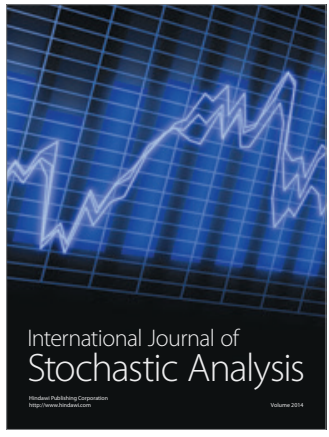

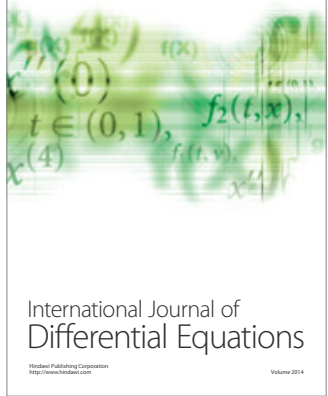
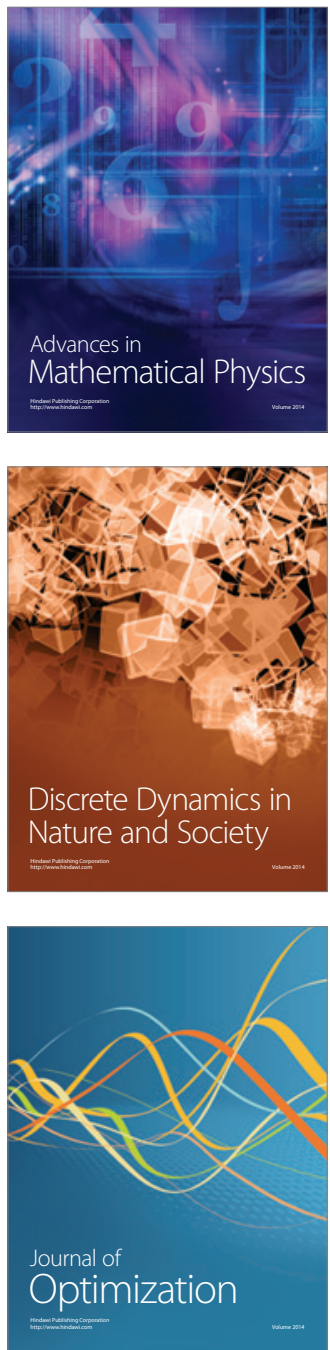